\title{
The Reliability of Surgical Apgar Score in Predicting Immediate and Late Postoperative Morbidity and Mortality: A Narrative Review
}

\author{
Abhijit Nair, M.D.*, Aanchal Bharuka, D.A., D.N.B., and Basanth Kumar Rayani, \\ D.A., D.N.B. \\ Department of Anesthesiology, Basavatarakam Indo-American Cancer Hospital and Research Institute, \\ Hyderabad, Telangana, India
}

\begin{abstract}
Surgical Apgar Score is a simple, 10-point scoring system in which a low score reliably identifies those patients at risk for adverse perioperative outcomes. Surgical techniques and anesthesia management should be directed in such a way that the Surgical Apgar Score remains higher to avoid postoperative morbidity and mortality.
\end{abstract}

KEY WORDS: Apgar score, morbidity, mortality, postoperative complications, risk factors, surgery

\section{INTRODUCTION}

Surgical risk scoring is important to predict postoperative outcomes, to plan admission to the intensive care unit (ICU), to prognosticate the general condi-

tion of the surgical patient, and to plan specific interventions postoperatively. A unit which is not fully equipped with multispecialty areas could plan

\begin{abstract}
Abbreviations: APACHE, Acute Physiology and Chronic Health Evaluation; ASA-PS, American Society of Anesthesiologists-Physical Status; GCS, Glasgow Coma Score; ICU, intensive care unit; POSSUM, Physiological and Operative Severity Score for the Enumeration of Mortality and Morbidity; P-POSSUM, Portsmouth modification POSSUM; SAPS, Simplified Acute Physiology Score; SAS, Surgical Apgar Score.

Citation: Nair A, Bharuka A, Rayani BK. The Reliability of Surgical Apgar Score in Predicting Immediate and Late Postoperative Morbidity and Mortality: A Narrative Review. Rambam Maimonides Med J 2018;9 (XX):eooo4. Review. doi:10.5041/RMMJ.10316
\end{abstract}

Copyright: (C) 2018 Nair et al. This is an open-access article. All its content, except where otherwise noted, is distributed under the terms of the Creative Commons Attribution License (http://creativecommons.org/licenses/by/3.0), which permits unrestricted use, distribution, and reproduction in any medium, provided the original work is properly cited.

Conflict of interest: No potential conflict of interest relevant to this article was reported.

* To whom correspondence should be addressed. E-mail: abhijitnair95@gmail.com 
transfer of a patient to a more specialized center based on the risk score.

Virginia Apgar, an anesthesiologist, described the 10-point scoring system, the Apgar score, in 1952 for assessing newborn babies. ${ }^{1}$ Scoring is done at $1 \mathrm{~min}$ and $5 \mathrm{~min}$ after birth. The score is helpful in predicting overall outcome after resuscitation of a child. Anesthesiologists and surgeons anticipate the perioperative events involved after major surgeries (laparotomies, resection/anastomosis, vascular surgery, neurosurgeries, emergency or urgent surgery) on the basis of factors like age, associated co-morbidities, surgical blood loss, and surgery duration. An otherwise uneventful intraoperative course does not predict the postoperative course in any patient. Complications occurring after surgery, especially after patient discharge, lead to increased morbidity, increased cost of treatment in the form of hospital admissions, and unwanted interventions.

\section{THE RISK SCORING SYSTEMS}

The Physiological and Operative Severity Score for the Enumeration of Mortality and Morbidity (POSSUM), the Simplified Acute Physiology Score (SAPS), and Acute Physiology and Chronic Health Evaluation (APACHE) scoring systems have been used to predict postoperative course.

Copeland et al. initially described POSSUM in 1991, for predicting morbidity and mortality of surgical patients. ${ }^{2}$ In 1998, the Portsmouth modification or the P-POSSUM was described. The PPOSSUM was found to be more reliable and accurate when compared to the POSSUM described by Copeland. 3 Twelve physiologic variables and six operative variables are used by POSSUM (Table 1 ).
Although P-POSSUM also uses the same indices that are used for POSSUM, the equation used to calculate the score is different. All the values have to be entered, and the score is derived either by adding up or by using software. Moreover, many investigations such as hemoglobin, urea, white cell count, sodium, potassium, and electrocardiogram are required. Surgical events are also used for scoring (peritoneal soiling, multiple surgeries). There could be a lot of personal differences when certain entries are made like assessment of surgery and respiratory status. In addition, POSSUM is not applicable for trauma patients, and an overestimation of POSSUM is possible in hepatopancreatobiliary surgeries. 4

Another score used to predict outcomes in medical and surgical patients is the Simplified Acute Physiology Score (SAPS). The SAPS II is used to score the status of patients admitted in the intensive care unit (ICU). It includes 17 variables: 12 physiologic variables, age, type of admission, and 3 disease-related variables. The SAPS II score registers the worst value of selected variables within the first $24 \mathrm{~h}$ after admission and can have a score between $\mathrm{o}$ and 163 points ( $\mathrm{o}-116$ points for physiologic variables, $\mathrm{O}-17$ points for age, and $\mathrm{o}-30$ points for previous diagnosis). Logistic regression is used to calculate the probability of death. 5

The Acute Physiology and Chronic Health Evaluation (APACHE) II was developed using a database of North American ICU patients in $1985 .{ }^{6}$ It uses a score derived from 12 routine physiologic measurements taken during the first $24 \mathrm{~h}$ after admission, age, and previous medical issues to provide information about the severity of disease. A score from o to 71 is calculated based on these measurements. A higher score signifies a more severe disease with

Table 1. The 12 Physiologic Indices and Six Operative Indices Used for Calculating the POSSUM Score.

\begin{tabular}{l:l|l|}
\hline \multicolumn{2}{|c|}{ Physiologic Indices } & \multicolumn{1}{|c|}{ Operative Indices } \\
\hline Age & Hemoglobin & Operative severity \\
Cardiac history & White cell count & Multiple surgeries \\
Respiratory history & Urea & Total blood loss \\
Pulse rate & Sodium & Peritoneal spillage \\
Blood pressure & Potassium & Malignancy \\
Glasgow coma scale & Electrocardiogram & Mode of surgery \\
\hline
\end{tabular}

A total of 18 indices must be entered to derive a POSSUM score. The score could be unreliable if any one index is missing. 
greater risk of death. The APACHE II has been used to prognosticate acutely ill patients and has helped researchers to compare the efficacy of various forms of treatment modalities. However, APACHE II led to an overestimation of mortality as physiologic variables used were dynamic and kept changing during treatment. Later APACHE III was introduced with two new variables: patient origin and the lead-time bias. Here, the score varied between 0 and 299 points.7 Later, APACHE IV was introduced in which another five variables were added: mechanical ventilation, thrombolysis, impact of sedation on Glasgow Coma Score (GCS), re-scaled GCS, and $\mathrm{PaO}_{2} / \mathrm{FiO}_{2}$ (arterial oxygen tension and fractional concentration of inspired oxygen) ratio. ${ }^{8}$

The SAPS and APACHE were found to be more reliable in predicting severity of condition and outcomes in medical patients when compared to surgical patients. ${ }^{9}$ Rapsang et al. have described nine routinely used scoring systems for predicting the morbidity and mortality of patients admitted in the ICU. The authors felt that selecting an inappropriate scoring methodology could lead to a significant waste of time, unwanted investigations, increased cost, and unwarranted extrapolations. ${ }^{10}$ Anesthesiologists use the American Society of AnesthesiologistsPhysical Status (ASA-PS) classification for describing patients based on co-morbidities, functional status, and emergency or elective surgery. The ASAPS was not designed to predict the mortality of a surgical patient. The ASA classification, with a positive predictive value of $57 \%$ for complications and a negative predictive value of $80 \%$, is not considered reliable for predicting the 30 -day postoperative course accurately. ${ }^{11}$

\section{THE SURGICAL APGAR SCORE}

Gawande et al. described the Surgical Apgar Score (SAS) in 2007.12 The score was derived from a retro- spective analysis of 303 patients who underwent colectomy at Brigham and Women's Hospital, Boston, MA. This 10-point score is based on the patient's surgical blood loss, the lowest intraoperative heart rate, and lowest recorded mean arterial pressure. The authors observed that as the score increased, outcomes improved at the end of 30 days. Many papers (discussed later on in this article) were subsequently published that interpreted prospective and retrospective data and concluded that SAS could accurately predict morbidity and complications in several surgical subspecialties. The SAS uses a 10point scoring system that has been used to accurately predict early and 30-day postoperative complications in all major surgeries in the last decade. The 10-point SAS is shown in Table 2.

\section{APPLICATION OF SAS BY OTHER RESEARCHERS IN OTHER SURGERIES}

The correlation of SAS with perioperative morbidity and complications was different when used in different subspecialties by different researchers. However, when the patient's ASA-PS classification was adjusted using relevant software, SAS scores remained associated with death and complications in several subspecialties. We searched PubMed, Scopus, Embase, and Google Scholar databases with the keywords "Surgical Apgar Score," "Postoperative complications," "Surgery," "Morbidity," and "Mortality" and identified 25 retrospective studies and 11 prospective studies that used SAS as a prognosticator tool to correlate with early and late postoperative complications (up to 30 days). The details of the retrospective and prospective data, type of surgical patients reviewed, total number of patients reviewed, and the reliability of SAS in predicting postoperative events are presented in Tables 3 and $4 .{ }^{13-49}$ Most of the published papers that have investigated the efficacy of SAS are based on retrospective data collected

Table 2. The 10-point Surgical Apgar Score.

\begin{tabular}{lcc|c|c|c|}
\hline Parameters & 0 Points* & 1 Point & 2 Points & 3 Points & 4 Points \\
\hline Estimated blood loss $(\mathrm{mL})$ & $>1000$ & $601-1000$ & $101-600$ & $\leq 100$ & - \\
Lowest mean arterial pressure $(\mathrm{mmHg})$ & $<40$ & $40-54$ & $55-69$ & $\geq 70$ & - \\
Lowest heart rate (beats/min) & $>85$ & $76-85$ & $66-75$ & $56-65$ & $\leq 55$ \\
\hline
\end{tabular}

* Occurrence of pathological bradyarrhythmia (including sinus arrest, atrioventricular block of dissociation, junctional or ventricular escape rhythms) and asystole also receives 0 points for lowest heart rate.

Reprinted from Gawande et al. ${ }^{12}$, (2007, with permission from the American College of Surgeons. 
Table 3. All Retrospective Studies Using SAS Scores for Various Surgeries to Predict Immediate and Delayed Postoperative Complications ( 30 days).

\begin{tabular}{|c|c|c|}
\hline Surgery Type (\# of Patients) Ref. & $\begin{array}{l}\text { Prognostic } \\
\text { Value (Y/N) }\end{array}$ & Remarks \\
\hline Knee arthroplasty $(3,511)^{13}$ & No & $\begin{array}{l}\text { The authors felt SAS was insufficient for } \\
\text { prognostication }\end{array}$ \\
\hline Colectomy $(795)^{14}$ & Yes & $\begin{array}{l}\text { SAS predicted inpatient as well as late post- } \\
\text { discharge complications }\end{array}$ \\
\hline General/vascular surgery $(4,119)^{15}$ & Yes & \\
\hline $\begin{array}{l}\text { Major intra-abdominal surgeries } \\
(8,501)^{16}\end{array}$ & Yes & \\
\hline Esophagectomy $(189)^{17}$ & Yes & $\begin{array}{l}\text { SAS predicted major morbidity associated with } \\
\text { longer hospital stay }\end{array}$ \\
\hline Esophagectomy $(168)^{18}$ & Yes & \\
\hline Ivor Lewis $(234)^{19}$ & No & SAS could not predict adverse outcomes \\
\hline Esophagectomy $(399)^{20}$ & Yes & \\
\hline Gastrectomy $(328)^{21}$ & No & $\begin{array}{l}\text { Original SAS not found useful; modified SAS was } \\
\text { helpful in predicting complications }\end{array}$ \\
\hline Hysterectomy for malignancy $(632)^{22}$ & No & SAS uncorrelated with postoperative events \\
\hline Pancreatoduodenectomy $(2012)^{23}$ & Yes & \\
\hline $\begin{array}{l}\text { Intracranial and spine neurosurgery } \\
(918)^{24}\end{array}$ & Yes & \\
\hline Surgery for spinal metastasis $(97)^{25}$ & No & $\begin{array}{l}\text { SAS an insignificant predictor of major perioperative } \\
\text { complications following spinal metastasis surgery; } \\
\text { preoperative functional status and age were } \\
\text { stronger predictors }\end{array}$ \\
\hline Lower extremity amputations $(228)^{26}$ & Yes & Predicted potential development of complications \\
\hline Wide surgical subspecialties $(123,864)^{27}$ & Yes & \\
\hline Intracranial meningioma excision $(999)^{28}$ & Yes & SAS predicted early and late complications \\
\hline Pancreatoduodenectomy $(103)^{29}$ & Yes & $\begin{array}{l}\text { SAS was a significant independent risk factor for } \\
\text { overall and recurrence-free survival }\end{array}$ \\
\hline Radical prostatectomy $(994)^{30}$ & Yes & \\
\hline Lumbar spine fusion $(199)^{31}$ & Yes & \\
\hline Gastrectomy $(191)^{32}$ & Yes & SAS predicted survival after surgery \\
\hline Major intra-abdominal surgery $(629)^{33}$ & Yes & SAS predicted survival after surgery \\
\hline Kidney transplant $(204)^{34}$ & Yes & $\begin{array}{l}\text { SAS correlated with ICU stay and overall cost of } \\
\text { treatment }\end{array}$ \\
\hline $\begin{array}{l}\text { Microvascular head and neck } \\
\text { reconstruction }(154)^{35}\end{array}$ & No & SAS uncorrelated with postoperative complications \\
\hline $\begin{array}{l}\text { Surgery for traumatic hip fractures } \\
(43)^{36}\end{array}$ & Yes & \\
\hline Pancreatic resection $(143)^{37}$ & Yes & $\begin{array}{l}\text { SAS along with hypoalbuminemia and blood } \\
\text { transfusion correlated well with hospital stay and } \\
\text { complications }\end{array}$ \\
\hline $\begin{array}{l}\text { Major gastrointestinal surgeries } \\
(1,833)^{38}\end{array}$ & Yes & $\begin{array}{l}\text { The authors modified SAS by including } \\
\text { intraoperative blood transfusion and assigned zero } \\
\text { estimated blood loss (EBL) score to patients who } \\
\text { received transfusion; they concluded that } \\
\text { intraoperative transfusion improved risk } \\
\text { stratification of SAS }\end{array}$ \\
\hline
\end{tabular}


Table 4. Prospective Studies Using SAS Scores for Various Surgeries to Predict Immediate and Delayed Postoperative Complications (30 days).

\begin{tabular}{|c|c|c|}
\hline $\begin{array}{l}\text { Surgery Type (\# of Patients) } \\
\text { Ref. }\end{array}$ & $\begin{array}{l}\text { Prognostic Value } \\
\text { (Y/N/Insignificant) }\end{array}$ & Remarks \\
\hline General/vascular surgery $(143)^{39}$ & Insignificant & Suggested conducting randomized control trial \\
\hline Spine $(268)^{40}$ & Yes & \\
\hline General orthopedic $(723)^{41}$ & No & $\begin{array}{l}\text { SAS did not predict } 30 \text {-day major } \\
\text { complications after general orthopedic } \\
\text { surgery }\end{array}$ \\
\hline Radical cystectomy $(155)^{42}$ & Yes & \\
\hline General surgery $(2,125)^{43}$ & Yes & \\
\hline Laparotomy $(218)^{44}$ & Yes & \\
\hline Non-cardiac surgeries $(5,909)^{45}$ & Yes & \\
\hline $\begin{array}{l}\text { General and vascular surgeries } \\
(224)^{46}\end{array}$ & Yes & \\
\hline $\begin{array}{l}\text { General, vascular, and } \\
\text { orthopedic surgeries }(223)^{47}\end{array}$ & Yes & $\begin{array}{l}\text { SAS uncorrelated with orthopedic patients } \\
\text { who had major events }\end{array}$ \\
\hline Renal mass excision $(886)^{48}$ & Yes & \\
\hline $\begin{array}{l}\text { High-risk intra-abdominal } \\
\text { surgeries }(355)^{49}\end{array}$ & Yes & $\begin{array}{l}\text { SAS was significantly predictive but weakly } \\
\text { discriminative for adverse events }\end{array}$ \\
\hline
\end{tabular}

from electronic hospital records; the SAS was calculated from the records. The authors used univariate and multivariate analyses to assess factors associated with major postoperative complications. Data collected from the National Surgical Quality Improvement Program underwent logistic regression using 27 preoperative variables as predictors; the outcome was determined by using the incidence of major postoperative complications to generate a multivariable preoperative risk prediction model.

Twenty out of 25 retrospective studies concluded that SAS correlated with adverse postoperative events. The SAS could not predict unfavorable events in patients who underwent knee arthroplasties (Wuerz et al. ${ }^{13}$ ), hysterectomy for malignancy (Clark et al. ${ }^{22}$ ), Ivor Lewis esophagectomies (Strøyer et al. ${ }^{19}$ ), spine surgery for metastasis (Lau et al. ${ }^{25}$ ), gastrectomy (Miki et al. ${ }^{21}$ ), and microvascular head and neck reconstruction (Ettinger et al.35). The authors felt that preoperative functional status and age were stronger predictors than SAS. Out of the 11 prospective studies, one study that analyzed patients undergoing orthopedic surgeries suggested that SAS could not predict adverse surgical outcomes. Haddow et al.39 analyzed 143 general and vascular surgical patients, and suggested conducting a randomized control trial due to the few cases, which provided inconclusive data. Thorn et al. 47 found that general and vascular surgery patients with a lower SAS correlated well with postoperative outcomes. However, there was poor correlation in orthopedic patients. The initial hypotension that occurs after administering a spinal anesthetic may explain the poor SAS correlation of postoperative events in these patients.

Hypotension usually improves with crystalloid boluses or a few doses of vasopressors. House et al.50 retrospectively analyzed data from 2007-2012 and found that a low SAS score was due to increased cardiac troponin levels after non-cardiac surgery. Out of 46,799 patients, 209 (0.4\%) had increased troponins and 192 (0.4\%) patients experienced myocardial infarction following non-cardiac surgeries. $5^{\circ}$ Jering et al. $5^{1}$ used the Area Under the Receiver Operating Characteristic Curve (AUROC) and suggested that combining ASA physical classification with continuously measured SAS was better in predicting major postoperative complications than using ASA physical status and SAS alone. ${ }^{1}$ 


\section{DISCUSSION}

An ideal surgical risk scoring system should be simple; require minimal calculation, data and variables; be reasonably accurate; and must be objective, economical, and suitable for all situations (elective/ emergency surgeries and valid in all specialties). The SAS is a simple way to predict complications during the postoperative period. It is a simple and inexpensive scoring system that can reliably predict serious postoperative consequences relying on only three variables. Patients undergoing major thoracic, abdominal, and vascular surgeries with significant co-morbidities are expected to have adverse perioperative outcomes. In spite of this, the SAS was able to predict either alone, or in combination with associated risk factors, the occurrence of lifethreatening events in the postoperative period. A patient with a low intraoperative SAS should be considered at risk and monitored meticulously. A patient with a low SAS should be monitored for an extended period in the ICU.

The SAS does not appear to correlate well with surgeries performed under regional anesthesia (e.g. arthroplasties, as shown by Wuerz et al. ${ }^{13}$ and Thorn et al.47). Well-designed prospective studies in the future could provide better insight into the reason behind the lack of correlation between regional anesthesia and SAS. The score could also help surgeons to improve or change their practice. This might include, for example, preventing surgical bleeds by meticulous use of electrocautery, identifying and ligating possible bleeders, and/or using a tourniquet whenever possible; giving time for bleeding to maintain mean arterial pressure (MAP); and avoiding events that lead to severe bradycardia by using slow insufflations after port insertion, maintaining normal intra-abdominal pressure, and avoiding forceful omental/peritoneal handling.

Hyder et al. $5^{2}$ investigated the effect on the SAS of different sampling methods for extracting vital signs data. In the study that involved more than 3,ooo patients, they found that larger SAS sampling intervals resulted in better model discrimination and improved reclassification. The authors had a large sample size, studied a variety of non-cardiac surgeries, and had a detailed classification of preoperative and postoperative morbidity. Optimized algorithms and larger sampling intervals of required parameters are needed to use SAS to predict patients at risk for adverse postoperative events. Smaller sampling intervals could lead to inadequate data, leading the investigator to find SAS unsatisfactory in predicting adverse outcomes.

\section{CONCLUSION}

The SAS is a simple 10-point scoring system that can be easily calculated and entered in case records at the end of surgery. Unlike other scoring systems, SAS does not require biochemical investigations, clinical assessment, acute or chronic disease classification, or depend on the timing of the surgery (elective, urgent, emergency). The patient with a low SAS could experience adverse perioperative lifethreatening events during the first 30 days of the postoperative period. Using SAS helps to identify patients at risk, and contributes to post-procedural auditing with evidence-based methodologies to help achieve the highest possible SAS in a surgical patient. In addition, SAS along with ASA-PS and larger sampling intervals could help to identify patients in need of monitoring and vigilant followup during the postoperative period.

\section{REFERENCES}

1. Apgar V. A proposal for a new method of evaluation of the newborn infant. Curr Res Anesth Analg 1953; 32:260-7. Crossref

2. Copeland GP, Jones D, Walters M. POSSUM: a scoring system for surgical audit. Br J Surg 1991;78:35660. $\underline{\text { Crossref }}$

3. Prytherch DR, Whiteley MS, Higgins B, Weaver PC, Prout WG, Powell SJ. POSSUM and Portsmouth POSSUM for predicting mortality. Br J Surg 1998;85: 1217-20. $\underline{\text { Crossref }}$

4. Wang H, Chen T, Wang H, Song Y, Li X, Wang J. A systematic review of the Physiological and Operative Severity Score for the enumeration of Mortality and morbidity and its Portsmouth modification as predictors of post-operative morbidity and mortality in patients undergoing pancreatic surgery. Am J Surg 2013;205:466-72. 당s

5. Le Gall JR, Lemeshow S, Saulnier F. A new Simplified Acute Physiology Score (SAPS II) based on a European/North American multicenter study. JAMA 1993;270:2957-63. Crossref

6. Knaus WA, Draper EA, Wagner DP, Zimmerman JE. APACHE II: a severity of disease classification system. Crit Care Med 1985;13:818-29. $\underline{\text { Crossref }}$

7. Knaus WA, Wagner DP, Draper EA, et al. The APACHE III prognostic system. Risk prediction of hospital mortality for critically ill hospitalized adults. Chest 1991;100:1619-36. $\underline{\text { Crossref }}$ 
8. Zimmerman JE, Kramer AA, McNair DS, Malila FM, Shaffer VL. Intensive care unit length of stay: benchmarking based on Acute Physiology and Chronic Health Evaluation (APACHE) IV. Crit Care Med 2006;34:2517-29. Crossref

9. Gilani MT, Razavi M, Azad AM. A comparison of Simplified Acute Physiology Score II, Acute Physiology and Chronic Health Evaluation II and Acute Physiology and Chronic Health Evaluation III scoring system in predicting mortality and length of stay at surgical intensive care unit. Niger Med J 2014;55: 144-7. Crossref

10. Rapsang AG, Shyam DC. Scoring systems in the intensive care unit: a compendium. Indian J Crit Care Med 2014;18:220-9. Crossref

11. Barnett S, Moonesinghe SR. Clinical risk scores to guide perioperative management. Postgrad Med J 2011;87:535-41. Crossref

12. Gawande AA, Kwaan MR, Regenbogen SE, Lipsitz SA, Zinner MJ. An Apgar score for surgery. J Am Coll Surg 2007;204:201-8. Crossref

13. Wuerz TH, Regenbogen SE, Ehrenfeld JM, Malchau H, Rubash HE, Gawande AA. The Surgical Apgar Score in hip and knee arthroplasty. Clin Orthop Relat Res 2011;469:1119-26. $\underline{\text { Crossref }}$

14. Regenbogen SE, Bordeianou L, Hutter MM, Gawande AA. The intraoperative Surgical Apgar Score predicts post-discharge complications after colon and rectal resection. Surgery 2010;148:559-66. $\underline{\text { Crossref }}$

15. Regenbogen SE, Lancaster RT, Lipsitz SR, Greenberg CC, Hutter MM, Gawande AA. Does the Surgical Apgar Score measure intraoperative performance? Ann Surg 2008;248:320-8. Crossref

16. Sobol JB, Gershengornayley B, Wunsch H, Li G. The Surgical Apgar Score is strongly associated with ICU admission after high-risk intra-abdominal surgery. Anesth Analg 2013;117:438-46. $\underline{\text { Crossref }}$

17. Xing XZ, Wang HJ, Qu SN, et al. The value of esophagectomy Surgical Apgar Score (eSAS) in predicting the risk of major morbidity after open esophagectomy. J Thorac Dis 2016;8:1780-7.

18. Janowak CF, Blasberg JD, Taylor L, Maloney JD, Macke RA. The Surgical Apgar Score in esophagectomy. J Thorac Cardiovasc Surg 2015;150:806-12. Crossref

19. Strøyer S, Mantoni T, Svendsen LB. Evaluation of the Surgical Apgar Score in patients undergoing IvorLewis esophagectomy. J Surg Oncol 2017;115:186-91. Crossref

20. Eto K, Yoshida N, Iwatsuki M, et al. Surgical Apgar Score predicted postoperative morbidity after esophagectomy for esophageal cancer. World J Surg 2016;40:1145-51. Crossref

21. Miki Y, Tokunaga M, Tanizawa Y, Bando E, Kawamura T, Terashima M. Perioperative risk assessment for gastrectomy by Surgical Apgar Score. Ann Surg Oncol 2014;21:2601-7. Crossref

22. Clark RM, Lee MS, Alejandro Rauh-Hain J, et al. Surgical Apgar Score and prediction of morbidity in women undergoing hysterectomy for malignancy. Gynecol Oncol 2015;136:516-20. Crossref

23. Assifi MM, Lindenmeyer J, Leiby BE, et al. Surgical Apgar Score predicts perioperative morbidity in patients undergoing pancreaticoduodenectomy at a high-volume center. J Gastrointest Surg 2012;16: 275-81. $\underline{\text { Crossref }}$

24. Ziewacz JE, Davis MC, Lau D, et al. Validation of the Surgical Apgar Score in a neurosurgical patient population. J Neurosurg 2013;118:270-9. Crossref

25. Lau D, Yee TJ, La Marca F, Patel R, Park P. Utility of the Surgical Apgar Score for patients who undergo surgery for spinal metastasis. Clin Spine Surg 2016 Jun 28. [Epub ahead of print]

26. Wied C, Foss NB, Kristensen MT, Holm G, Kallemose T, Troelsen A. Surgical Apgar Score predicts early complication in transfemoral amputees: retrospective study of 170 major amputations. World J Orthop 2016;7:832-8. Crossref

27. Reynolds PQ, Sanders NW, Schildcrout JS, Mercaldo ND, St Jacques PJ. Expansion of the Surgical Apgar Score across all surgical subspecialties as a means to predict postoperative mortality. Anesthesiology 2011; 114:1305-12. $\underline{\text { Crossref }}$

28. Hsu SY, Ou CY, Ho YN, Huang YH. Application of Surgical Apgar Score in intracranial meningioma surgery. PLoS One 2017;12:e0174328 $\underline{\text { Crossref }}$

29. Aoyama T, Kazama K, Murakawa M, et al. The Surgical Apgar Score is an independent prognostic factor in patients with pancreatic cancer undergoing pancreatoduodenectomy followed by adjuvant chemotherapy. Anticancer Res 2016;36:2497-503.

30. Orberger M, Palisaar J, Roghmann F, et al. Association between the Surgical Apgar Score and perioperative complications after radical prostatectomy. Urol Int 2017;98:61-70. Crossref

31. Ou CY, Hsu SY, Huang JH, Huang YH. Surgical Apgar Score in patients undergoing lumbar fusion for degenerative spine diseases. Clin Neurol Neurosurg 2017;152:63-67. $\underline{\text { Crossref }}$

32. Yamada T, Tsuburaya A, Hayashi T, et al. Usefulness of Surgical Apgar Score on predicting survival after 
surgery for gastric cancer. Ann Surg Oncol 2016; 23(Suppl 5):757-63. $\underline{\text { Crossref }}$

33. Masi A, Amodeo S, Hatzaras I, et al. Use of the Surgical Apgar Score to enhance Veterans Affairs Surgical Quality Improvement Program surgical risk assessment in veterans undergoing major intra-abdominal surgery. Am J Surg 2017;213:696-705. Crossref

34. Stoll WD, Taber DJ, Palesch SJ, Hebbar L. Utility of the Surgical Apgar Score in kidney transplantation: is it feasible to predict ICU admission, hospital readmission, length of stay, and cost in this patient population? Prog Transplant 2016;26:122-8. Crossref

35. Ettinger KS, Moore EJ, Lohse CM, Reiland MD, Yetzer JG, Arce K. Application of the Surgical Apgar Score to microvascular head and neck reconstruction. J Oral Maxillofac Surg 2016;74:1668-77. $\underline{\text { Crossref }}$

36. Sakan S, Pavlovic DB, Milosevic M, Virag I, Martinovic P, Dobric I. Implementing the Surgical Apgar Score in patients with trauma hip fracture. Injury 2015;46(Suppl 6):S61-6. $\underline{\text { Crossref }}$

37. La Torre M, Ramacciato G, Nigri G, et al. Post-operative morbidity and mortality in pancreatic surgery. The role of Surgical Apgar Score. Pancreatology 2013; 13:175-9.

38. Ejaz A, Gani F, Frank SM, Pawlik TM. Improvement of the Surgical Apgar Score by addition of intraoperative blood transfusion among patients undergoing major gastrointestinal surgery. J Gastrointest Surg 2016;20:1752-9. $\underline{\text { Crossref }}$

39. Haddow J, Adwan H, Clark S, et al. Use of the Surgical Apgar Score to guide postoperative care. Ann R Coll Surg Engl 2014;96:352-8. $\underline{\text { Crossref }}$

40. Urrutia J, Valdes M, Zamora T, Canessa V, Briceno J. An assessment of the Surgical Apgar Score in spine surgery. Spine J 2015;15:105-9. 당s

41. Urrutia J, Valdes M, Zamora T, Canessa V, Briceno J. Can the Surgical Apgar Score predict morbidity and mortality in general orthopaedic surgery? Int Orthop 2012;36:2571-6. $\underline{\text { Crossref }}$

42. Prasad SM, Ferreria M, Berry AM, et al. Surgical Apgar outcome score: perioperative risk assessment for radical cystectomy. J Urol 2009;181:1046-52; discussion 1052-3. $\underline{\text { Crossref }}$
43. Melis M, Pinna A, Okochi S, et al. Validation of the Surgical Apgar Score in a veteran population undergoing general surgery. J Am Coll Surg 2014;218:21825. $\underline{\text { Crossref }}$

44. Ngarambe C, Smart BJ, Nagarajan N, Rickard J. Validation of the Surgical Apgar Score after laparotomy at a tertiary referral hospital in Rwanda. World J Surg 2017;41:1734-42. Crossref

45. Haynes AB, Regenbogen SE, Weiser G, et al. Surgical outcome measurement for a global patient population: validation of the Surgical Apgar Score in 8 countries. Surgery 2011;149:519-24. $\underline{\text { Crossref }}$

46. Ohlsson H, Winsö O. Assessment of the Surgical Apgar Score in a Swedish setting. Acta Anaesthesiol Scand 2011;55:524-9.

47. Thorn CC, Chan M, Sinha N, Harrison RA. Utility of the Surgical Apgar Score in a district general hospital. World J Surg 2012;36:1066-73. Crossref

48. Ito T, Abbosh PH, Mehrazin R, et al. Surgical Apgar Score predicts an increased risk of major complications and death after renal mass excision. J Urol 2015;193:1918-22. $\underline{\text { Crossref }}$

49. Cihoric M, Toft Tengberg L, Bay-Nielsen M, Bang Foss N. Prediction of outcome after emergency highrisk. intra-abdominal surgery using the Surgical Apgar Score. Anesth Analg 2016;123:1516-21. Crossref

50. House LM, Marolen KN, St Jacques PJ, McEvoy MD, Ehrenfeld JM. Surgical Apgar Score is associated with myocardial injury after noncardiac surgery. J Clin Anesth 2016;34:395-402. $\underline{\text { Crossref }}$

51. Jering MZ, Marolen KN, Shotwell MS, Denton JN, Sandberg WS, Ehrenfeld JM. Combining the ASA physical classification system and continuous intraoperative Surgical Apgar Score measurement in predicting postoperative risk. J Med Syst 2015;39:147. Crossref

52. Hyder JA, Kor DJ, Cima RR, Subramanian A. How to improve the performance of intraoperative risk models: an example with vital signs using the Surgical Apgar Score. Anesth Analg 2013;117:1338-46. Crossref 